\title{
10. Exploring Age - Transition Analysis as a Tool for Detecting the Elderly
}

\author{
NINA MAARANEN¹ AND JO BUCKBERRY²
}

\begin{abstract}
Maaranen, N. and Buckberry, J. 2018. Across the Generations: The Old and the Young in Past Societies. AmS-Skrifter 26, 143-154, Stavanger. ISSN 0800-0816, ISBN 978-82-7760-181-6.

The growth of gender archaeology has improved the inclusion of female and juvenile narratives in archaeological discourse, enabling us to better understand interactions between groups defined by both social and physiological differences. There has been a notable absence of elderly in research, however, that is not simply a question of attitudes but of methodological limitations. The emergence of biostatistics has offered novel ways to combat common issues such as age mimicry and avoid the problematic nature of culturally loaded descriptive terminology. A test performed on Transition Analysis by Boldsen et al. (2002), generates individual age estimates, which allow for better differentiation between individuals and age groups, such as the ' $45+$ older adults'. Further research into biostatistical methods will not only improve objectivity but bring much-needed attention to the elderly, including their narrative into the investigation of family dynamics and adult-juvenile interactions.
\end{abstract}

Keywords: Osteology; age estimation; biostatistics; Bayes' theorem; Transition Analysis

Addresses: Faculty of Science and Technology, Department of Archaeology, Anthropology and Forensic Science, Bournemouth University, Poole BH12 5BB, UK ${ }^{1}$; Biological Anthropology Research Centre, Archaeological Sciences, University of Bradford, Bradford BD7 1DP, UK². Emails: nmaaranen@bournemouth.ac.uk; J.Buckberry@bradford.ac.uk

\section{Introduction}

Age-at-death is used by a large range of disciplines assessing and interpreting skeletal changes. In archaeology, age assists in the construction of life histories as well as forming palaeodemographic profiles. To understand cultural age and its agency it is essential to estimate an age that is both precise and accurate. Precision refers to the closeness between the known age and the estimation, while accuracy describes the reliability of those estimations. However, the intrinsic (i.e. genetic) and extrinsic (such as environmental and habitual) factors governing the ageing process cause individuals of the same chronological age to exhibit different physiological ages (Uhl 2013, 69-70). This robusticity and adaptability ensures survival of the species, but is harrowing for the investigator. The lack of uniformity requires methods to balance between accuracy and precision in order to produce results that are still meaningful. Furthermore, as the effects of extrinsic factors accumulate with increasing age, so do the age ranges. This has caused a common practice to use terminal age intervals which begin as early as forty-five years of age. This not only skews our views of the age structure of past societies, leading to perceptions that in most past populations people did not survive past middle age (Van Gerven and Armelagos 1983; Meindl and Russell 1998; Milner and Boldsen 2012), but it also obscures the presence of the old, disrupting our understanding of the agency held by older individuals as well as the dynamics between groups.

Age is a relatively recent addition to the study of social identity in the archaeological context, especially in relation to the old (see Gilchrist 2000; Gowland 2006; 2007; Sofaer 2006; Appleby 2010). Many of the concepts have been assumed to the field from social history, such as the idea of age as a tripartite construction, consisting of physiological (biological), chronological and social age (Ginn and Arber 1995, 2). These terms have often been used interchangeably, which has been recognised as a symptom of disconnect between disciplines regarding the physiological attributes and social connotations of age, causing fundamental methodological problems (Gowland 2006, 144; Sofaer 2006, 124-5). Although age-related social events and physiological changes are often linked, assuming cross-cultural uniformity ignores the different values that might be assigned to 
these events in different cultures (Schildkrout 1978; La Fontaine 1986). Using verbal descriptions of age categories poses also a hermeneutic problem as modern values are imposed on foreign entities.

Understanding and reconstructing the complex webs of age identity is a challenging task, but recent methodological developments may offer some assistance. Biostatistics has introduced new ways of assessing skeletal material by offering a higher awareness of methodological implications and possibly removing some of the subjectivity of age estimation. In this chapter we describe the mechanics behind currently favoured age estimation methods (thus omitting histological and dental methods), explain the cause of the main issues plaguing these methods and introduce the 'new' statistical framework suggested for the analysis of age-at-death. Transition Analysis (Boldsen et al. 2002) is currently the only statistically sound method with readily applicable computer software and an easily understandable interface. Its reliability was tested on a Finnish skeletal collection, held by the Finnish Natural History Museum in Helsinki. Lastly, the results as well as the implications of using statistical approaches to age estimation are discussed.

\section{Estimating Age-at-death}

Some key developments have been recognised from the age estimation literature - increased awareness of the variation between individuals and populations from the perspective of secular trends and genetics, understanding the requirement for diversity in both methods and reference samples and, lastly, realising the need for more complex and sophisticated methods, disposed to vigorous testing (Ubelaker 2010, xxiii; DiGangi and Moore 2013, 509). Many of these issues have been known to researchers, at least to some extent, since the beginning of modern skeletal age-at-death estimations (e.g. Dwight 1878) but the analyses available through computing have allowed for a more analytical examination of methods and data. Over the past thirty years, researchers have identified methodological issues from the techniques most often favoured by investigators, such as misinterpretation (e.g. Saunders et al. 1992) and age mimicry (Bocquet-Appel and Masset 1982; Konigsberg and Frankenberg 1992).

Methods in Table 1 have come to represent the socalled conventional methods of adult age-at-death estimation (Garvin et al. 2012, 204). Despite concerning different regions of the skeleton, these methods have several things in common: they are all macroscopic (observable with the naked eye), they all assess degeneration (the 'wear and tear' of the skeleton) and they all use fixed age ranges and means.

The methods have been created by seriating individuals of known-ages-at-death, assessing the degenerative state of the skeletal landmark under investigation (also called age indicator) and exploring its relation to chronological age. In this process, the chronological age of the individual comes second to their physiological appearance. The results can be presented in either phases, where each stage is accompanied by a fixed descriptive, or as a sum of scores, where every aspect of the landmark is assessed separately to produce a final estimation (Konigsberg 2015). The phases and sum of scores then offer age categories, which are defined by the chronological ages of the individuals within it. Each category age range incorporates the majority of the individuals exhibiting the same physiological appearance, presenting phases either as confidence intervals with mean ages or as point estimates with standard deviations.

\section{Issues with Estimating Age-at-death}

The universality of ageing ensures a certain level of similarity, but cannot be extended much further than that, as variation can be observed not only between but within populations (Hoppa 2000; Kemkes-Grottenhaler 2002, 48 Garvin et al. 2012, 216). Decreasing the confidence interval to a lower percentage may increase precision at the expense of a true portrayal of the variation, while accurate age groupings with overlapping ranges may lose their usefulness as investigative tools (Buckberry 2015). The issue could be alleviated by using population-specific methods but this may be impossible for certain areas due to lack of appropriate reference samples and, as seen by Falys and Lewis (2011), investigators preferring to use the same methods regardless of the population.

A major issue with age estimation was noted when the palaeodemographic profiles created from target samples could not be found in ethnographic data, life tables or historical records (Chamberlain 2006, 90). Some of the cases may be an effect of differential burial, preservation or recovery as well as an actual representation of a catastrophic event that took place, but surely not all (Chamberlain 2000, 102-5). Bocquet-Appel and Masset (1982) noticed the discrepancy when comparing demographic profiles from historical sources to palaeodemographic ones, the latter producing distributions more similar to the reference sample. The phenomenon was coined as age 
Table 1: Regions and methods most often preferred by investigators according to studies by Garvin and Passalacqua (2011) and Falys and Lewis (2012). Short descriptions of the regions are included to increase awareness of the factors (other than age) affecting appearance.

\begin{tabular}{|c|c|c|c|c|c|}
\hline Area & Description of area & Method & Description of method & $\begin{array}{l}\text { Falys } \\
\text { and } \\
\text { Lewis } \\
\text { (2012) }\end{array}$ & $\begin{array}{l}\text { Garvin and } \\
\text { Passa- } \\
\text { lacqua } \\
\text { (2011) }\end{array}$ \\
\hline \multirow{3}{*}{$\begin{array}{l}\text { Pubic } \\
\text { symphysis }\end{array}$} & \multirow{3}{*}{$\begin{array}{l}\text { Amphiarthrodial joint, the opposing } \\
\text { elements separated by a hyaline cartilage } \\
\text { disc, capable of slight movement (c. } 2 \\
\mathrm{~mm} \text {, Becker et al. 2010). Oestrogen and } \\
\text { other female sex-related hormones cause } \\
\text { changes to the appearance, especially in } \\
\text { the form of sped up degeneration (Mays } \\
\text { 2015). }\end{array}$} & $\begin{array}{l}\text { Katz and } \\
\text { Suchey } 1986 ; \\
\text { Brooks and } \\
\text { Suchey } 1990\end{array}$ & $\begin{array}{l}739 \text { modern males and } 273 \text { females autopsied at } \\
\text { the Department of Chief Medical Examiner-Coroner, } \\
\text { County of Los Angeles, California, USA. Modified } \\
\text { Todd's (1921) method by reducing ten phases to six, } \\
\text { casts available, much variation in phases III-VI. }\end{array}$ & $55 \%$ & $95.3 \%$ \\
\hline & & $\begin{array}{l}\text { Todd 1920; } \\
1921\end{array}$ & $\begin{array}{l}\text { ca } 650 \text { individuals modern individuals collected at } \\
\text { the Anatomic Laboratory of the Western Reserve } \\
\text { University, Ohio, USA. Ten phases, systematically } \\
\text { over-ages (Katz and Suchey 1986). }\end{array}$ & $16 \%$ & $27.9 \%$ \\
\hline & & $\begin{array}{l}\text { McKern and } \\
\text { Stewart } 1957\end{array}$ & $\begin{array}{l}\text { Korean War dead, US Army. Three-component } \\
\text { system using mostly White males, less restrictive } \\
\text { than a phase system, however the components are } \\
\text { said to be connected (Katz and Suchey 1986). }\end{array}$ & . & $28.7 \%$ \\
\hline \multirow{3}{*}{$\begin{array}{l}\text { Auricular } \\
\text { surface }\end{array}$} & \multirow{3}{*}{$\begin{array}{l}\text { Synovial joint that allows for very little } \\
\text { movement (c. } 0.7 \text { mm, Stuerson et al. } \\
\text { 1989). The lliac portion of the sacroiliac } \\
\text { joint is covered by fibrocartilage which } \\
\text { has been observed to exhibit signs of } \\
\text { degeneration much earlier (Mays 2015). } \\
\text { The structure reacts to mechanical stress, } \\
\text { and changes have been connected to } \\
\text { body size (Merritt 2015; Wescott and Drew } \\
\text { 2015). }\end{array}$} & $\begin{array}{l}\text { Lovejoy et al. } \\
1985 \mathrm{~b}\end{array}$ & $\begin{array}{l}\text { Todd Collection (Ohio, USA), Libben Collection (Kent } \\
\text { State University, Ohio, USA) and forensic cases } \\
\text { provided by Cuyahoga County Coroner's Office. } \\
\text { Eight phases, age ranges do not overlap and the first } \\
\text { seven are very narrow, later tests have shown low } \\
\text { values for accuracy (Rissech et al. 2012). }\end{array}$ & $71 \%$ & $84.5 \%$ \\
\hline & & $\begin{array}{l}\text { Meindl and } \\
\text { Lovejoy } 1989\end{array}$ & $\begin{array}{l}\text { Revised Lovejoy et al. (1985) method on altogether } \\
261 \text { individuals from the Hamann-Todd Collection. }\end{array}$ & $12 \%$ & \\
\hline & & $\begin{array}{l}\text { Buckberry and } \\
\text { Chamberlain } \\
2002\end{array}$ & $\begin{array}{l}180 \text { individuals from Christ Church, Spitalfields, } \\
\text { London, UK. Five-component system, over-ages } \\
\text { the young (Mulhern and Jones 2005). Posterior } \\
\text { probabilities available to correct for bias caused by } \\
\text { reference sample, tested succesfully (e.g. Nagaoka } \\
\text { et al. 2012). }\end{array}$ & $4 \%$ & $39.5 \%$ \\
\hline $\begin{array}{l}\text { Sternal } \\
\text { end of } \\
\text { the rib }\end{array}$ & $\begin{array}{l}\text { Costochondral joint, formed by hyaline } \\
\text { cartilage and attached to the sternal ends } \\
\text { of the ribs (Mays 2015). Ossification } \\
\text { patterns are different for males and } \\
\text { females (Navani et al. 1970; Rejtarová et } \\
\text { al. 2009), and can be affected by changes } \\
\text { in especially sex hormones, vitamin D } \\
\text { deficiency, trauma (Sanders 1966; 1971; } \\
\text { Malghem et al. 2001; Gleize et al. 2007; } \\
\text { Mays 2015). }\end{array}$ & $\begin{array}{l}\text { İşcan et al. } \\
\text { 1984a; 1984b; } \\
1985\end{array}$ & $\begin{array}{l}\text { Created from the fourth rib of altogether } 297 \\
\text { autopsied individuals. Component system (İşcan et } \\
\text { al. 1984a) that turned into a phase system (Işcan } \\
\text { et al. 1984b), 4th rib morphology, differences noted } \\
\text { according to sex, occupation and ancestry (İşcan et } \\
\text { al. 1985; 1987; Işcan 1991). }\end{array}$ & $94 \%$ & $89.9 \%$ \\
\hline \multirow[t]{4}{*}{$\begin{array}{l}\text { Cranial } \\
\text { sutures }\end{array}$} & $\begin{array}{l}\text { Synarhtroses (made of fibrous collagen) } \\
\text { which usually ossify during life course. } \\
\text { Laboratory experiments on rats have } \\
\text { shown cranial sutures to be regulated by } \\
\text { the dura mater, controlled by a plethora } \\
\text { of proteins and hormones, and little- } \\
\text { investigated genetic properties (Mays } \\
\text { 2015; Wolff et al. 2013). }\end{array}$ & $\begin{array}{l}\text { Meindl and } \\
\text { Lovejoy } 1985\end{array}$ & $\begin{array}{l}236 \text { crania from the Hamann-Todd collection (Ohio, } \\
\text { USA). Four-component system, sutures are not very } \\
\text { informative (e.g. Milner and Boldsen 2012). }\end{array}$ & $40 \%$ & $61.2 \%$ \\
\hline & & $\begin{array}{l}\text { Dental attrition } \\
\text { (Brothwell } \\
\text { 1981) }\end{array}$ & $\begin{array}{l}\text { British skeletal remains from the Neolitchic to } \\
\text { Medieval times. Observing amount of wear, } \\
\text { population-specific (Brothwell 1981). }\end{array}$ & $51 \%$ & . \\
\hline & & $\begin{array}{l}\text { Dental attrition } \\
\text { (Lovejoy } \\
\text { 1985a) }\end{array}$ & $\begin{array}{l}\text { Mandibular and maxillar teeth from } 332 \text { individuals } \\
\text { from the Libben population. Attrition was correlated } \\
\text { with other age estimation methods. }\end{array}$ & $10 \%$ & . \\
\hline & & $\begin{array}{l}\text { Microscopic } \\
\text { methods }\end{array}$ & $\begin{array}{l}\text { Various histological methods concerning bone } \\
\text { and teeth. Destructive to material and require high } \\
\text { specialisation. }\end{array}$ & $1 \%$ & . \\
\hline
\end{tabular}


mimicry (Mensforth 1990) and refers to the event where the weakness of the age indicator causes the target sample distribution to mimic the distribution of the reference sample.

The problem arises from the use of regression analyses, where two imperfectly related factors are correlated against each other. The method has been used heavily in stature estimations, where it has a similar, though not as pronounced, problem to age indicators (see Moore and Ross 2013, 151-79). If the correlation between factors is perfect, regression supposes no issues, but in the case of skeletal age indicators the age derived from the inverse regression depends on the age distribution of the group (Masset 1989). In other words, if the age group exhibiting a certain typical trait is small, the trait may be more represented in a larger group, resulting in the misrepresentation of the 'typical age' for that trait. Further support was offered by Konigsberg and Frankenberg (1992) who noted that to avoid mimicry, the reference and target sample must have similar age structures, the reference sample age structure must have an equal number of individuals in every age group (to avoid peaking), or the age indicator must be perfect (Konigsberg and Frankenberg 1992). The first two conditions are challenging simply due to the limited number of available collections and, as already discussed, the existence of a perfect indicator for macroscopic examination seems unlikely (but see discussions of cementum annulations (Wittwer-Backofen et al. 2004; Naji et al. 2016) and the experienced based method currently being developed by Milner and Boldsen (2012, fig. 14)).

Different approaches have been suggested to remedy the situation, such as choosing the method according to a two-step procedure, combining estimations in a multifactorial manner and minimising the influence of the reference sample with Bayesian analysis. The selection of method in the two-step procedure (TSP) is determined by the state of the individual. Baccino et al. (2014) suggested a combination of the pubic symphysis method devised by Brooks and Suchey (1990) and the dental method of Lamendin et al. (1992), where the individuals falling within the first phases of Brooks and Suchey (1990) are assessed using the former and the individuals in the final phases with the latter. Multifactorial methods, on the other hand, take into account estimations from several methods at once in an attempt to gain a better overall accuracy (İşcan and Loth 1989; Meindl and Russell 1998). However, neither approach has a firm statistical leg to stand on. In TSP, the leap from one method to another is unjustified mathematically, while the combination of several age estimation methods with different error structures is equally problematic (Holman et al. 2002, 195; Baccino et al. 2014). Additionally, neither can address the issue caused by fixed age ranges. Bayesian analysis, though most effective, is currently the least employed.

\section{The Bayesian Approach}

Bayesian Theorem, the posthumously published work by Reverend Thomas Bayes (1701-61), estimates the probability of an event using a frequency already known (paraphrased from the fifth definition, Bayes and Price 1763, 376). Since its acceptance in the field of mathematics it has resolved issues in inferential statistics but it was not until the advent of computerised statistics, however, that the theorem extended into a more diverse set of fields (Stigler 1986, 6-7). Now an approach called Bayesian probability is even used in random walk techniques which do not follow the original principles of Bayes' theorem but allow the computation of a vast number of parameters. This is a key factor in the utilisation of the theory in multivariate age estimation. Several statisticians believe Bayesian theorem holds vast possibilities in the humanities (e.g. see Jackman 2009) as it takes into account the uncertainty and belief inherent in all qualitative work and creates a range of possibilities instead of just one. In age estimations it can be used in any feature, as long as the observed feature is unidirectional and cannot be skipped or reversed (Konigsberg and Frankenberg 1992).

The usefulness of biostatistical methods were recognised at two workshops held at the Max Planck Institute in June 1999 and August 2000, bringing together researchers wanting to determine a direction for future research. The culmination of these discussions formed a guideline, the Rostock Manifesto, with four major elements. First, the methods estimating age must be meticulously generated and widely tested. Second, the data collected must be biostatistically explored. Third, probabilities must be calculated for age indicators using a reference sample and the target sample. Fourth, the age distribution of the target sample must be estimated by calculating the distribution of the observed indicators. This creates the prior knowledge age structure, or 'prior' (Hoppa and Vaupel 2002, 2-3). The equation is:

$$
\operatorname{Pr}\left(a \mid c_{j}\right)=\frac{\operatorname{Pr}(c j \mid a) f(a)}{\int_{0}^{\infty} \operatorname{Pr}(c j \mid x) f(x) d x}
$$


- $\operatorname{Pr}(a \mid c)$ is the conditional probability of the individual being a certain age a when observing stage $j$ of feature $c$.

- $\operatorname{Pr}\left(\mathrm{c}_{j} \mid \mathrm{a}\right)$ is the probability of observing a stage $j$ in feature $c$ when the age $a$ is known.

- $f(\mathrm{a})$ is the prior distribution of ages-at-death of the sample in question.

- $x$ is age and $d$ is the unit of age.

This means that any age category, that is over-represented in a reference sample, can be assigned another value that 'corrects' for the bias, either by assuming any age presenting a certain feature are equally possible or assuming some ages to be more probable than others (Konigsberg and Frankenberg 1994; 2002). Ironically, the latter skews the data again, but in Bayesian analysis this skewing is conscious and is conducted using, paradoxically, prior knowledge of the target sample's probable age structure.

Since first applied to age by Konigsberg and Frankenberg (1992), its applications have gradually increased (Chamberlain 2000; Gowland and Chamberlain 2002; 2005; Prince et al. 2008; Godde and Hens 2012). However, the application of Bayesian probability as described in the Rostock Manifesto requires familiarity with statistical programs as well as a large target sample to create a prior age distribution. While the former may be overcome by practice, the latter is difficult to fix in single-individual samples, often present in forensic and archaeological cases. The auricular surface method of Buckberry and Chamberlain (2002) provides correction values for the auricular stages to account for the effects of the reference sample. These values have been shown to yield 'realistic age distributions' (Nagaoka and Hirata 2008; Nagaoka et al. 2012, 104) but, when testing the method, most researchers have opted to use the original values reflecting the reference sample instead (Buckberry 2015, 325).

\section{Transition Analysis}

As a solution for cases with small sample sizes, Boldsen and colleagues (2002) proposed that an external prior with a similar age distribution could be used instead. Instead of using fixed age ranges and means, Transition Analysis creates unique age ranges (confidence intervals), one for each skeletal region and a combined range with two point estimates (maximum likelihood estimates). The point estimates are generated from a uniform and an informative prior, the latter chosen by the user (see below).
The method was named Transition Analysis because it estimates the time when the individual transitions from one stage to the next. It does this by converting a generalised linear model into a cumulative logit model, which is used when there are more than two stages. However, the resulting logistic distribution has equal standard deviations to each stage which are known to lengthen with increasing age. The issue was resolved by employing a continuation ratio model that calculates the distribution by taking into account the preceding stages, thus accommodating the increasing variation (Boldsen et al. 2002, 81-6).

When created, the method assumed 'conditional independence' between traits to avoid becoming too heavy. This means all the correlations between age indicators is expected to be caused by age and there is no residual correlation from non-age-related factors. The idea that age indicators only showed correspondence through age had already been doubted (Katz and Suchey 1986; Holman et al. 2002, 195) and has since been refuted (Milner and Boldsen 2012). However, there is currently no readily applicable method that could account for residual correlation.

In Transition Analysis, skeletal landmarks are broken down into components. A total of nineteen features (thirty-three points per skeleton) are recorded: five features from both sides of the pubic symphysis, nine from both sides of the auricular surface and five suture loci from the left side of the cranium. The information has been collected from the American Terry Collection and the Portuguese Coimbra Collection (Milner and Boldsen 2012). Though the recording process is similar to many conventional methods using composite scores, Transition Analysis allows for missing features and 'inbetween' phases.

Scores are entered into ADBOU (a free computer programme available at http://math.mercyhurst. $\mathrm{edu} / \sim$ sousley/Software) which provides the estimator with a uniform (uninformative) and two informative probability distributions, or priors. The uniform distribution does not assume any age to be more likely than others, whereas the informative priors give emphasis to certain age groups. The priors provided by the programme, named forensic and archaeological, differ in age structure and are intended to be used as a reflection of the assumed age structure of the target sample. The forensic prior has a bias towards the young, while the archaeological prior is more reflective of a normal population demographic profile (Peters et al. 1998; Johansen 2002). 


\section{Materials and Methods}

The validation study presented here was performed as partial fulfilment of a Master's degree at the University of Bradford. Transition Analysis was tested on Series A, a known age-at-death sample from a larger skeletal collection held at the Finnish Museum of Natural History in Helsinki. The Helsinki collection in its entirety is diverse, ranging from archaeological finds to miscellaneous donations. The material was collected by researchers at the University of Helsinki between 1839 and the end of WWII; Series A was collected mainly in 1914-16 and 1928-37 for teaching and research purposes. It consists of 201 adult individuals of which 189 have information such as name, sex, age, birth date and place, occupation and cause of death. Nearly half of the collection has been curated from prisons, the rest mostly from elderly homes and poorhouses (Söderholm 2002, 36-9). Previous research has been conducted on the collection by Telkkä $(1949 ; 1950)$ and Niinimäki (2012).

Due to the recent dates of the collection, the catalogue information is not yet public record and all sensitive information has been omitted here according to the guidelines provided by the Finnish Museum of Natural History. Sub-sampling was necessary as not all skeletal elements had been collected, lowering the number of individuals to either eighty-six (individuals with recordable features in either the cranium or os coxae) or sixty-eight (individuals with at least os coxae present). The skeletons had a varying number of features present for estimation, a point that would create an issue for conventional methods. The sub-sample age distributions were nearly identical; the larger subsample of eighty-six individuals had an age range of 18-91 years (mean 44.3, median 40 and mode 27), while that of the smaller sample of sixty-eight individuals was $18-87$ years (mean 43.3 , median 39 and mode 27).

The material was assessed using the Transition Analysis method of Boldsen et al. (2002), the BuckberryChamberlain auricular surface method (2002) and the Suchey-Brooks pubic symphysis method (1990). The Buckberry-Chamberlain and Suchey-Brooks methods were selected for their different reference sample age structures to fully observe the effects of reference sample bias. Examiners should be aware of the factors (besides age) underpinning morphological appearance in age indicators (see Table 1). The skeletons were recorded blind to known age and sex. Due to spatial limitations each method was analysed at the same time for the entire skeleton, but covering the side not under evaluation. Scores were first recorded by hand and not entered into the programme until data collection was completed.

The estimations were assessed for accuracy, inaccuracy and bias. Accuracy is calculated by dividing the sum of successful estimations (cases where true age falls within the estimated age range) with both successful and unsuccessful estimations (number of successful cases/all cases). The result is presented as a percentage (\%) success rate. Inaccuracy is the difference between the maximum likelihood estimate and the true age, while bias measured the skewness of the difference (i.e. whether individuals are systematically over- or

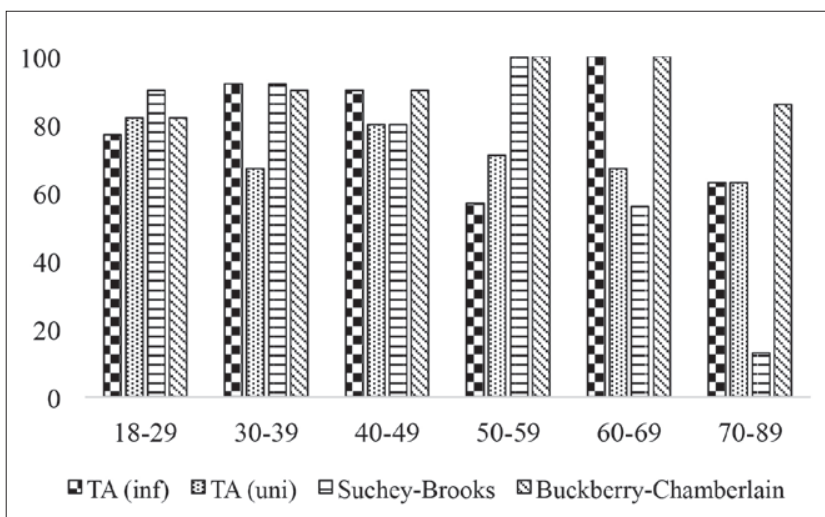

Figure 1: Accuracy (\%) according to age categories for informative and uniform Transition Analysis (TA) by Boldsen et al. (2002), Suchey-Brooks (1990) pubic symphysis method and Buckberry-Chamberlain (2002) auricular surface method.

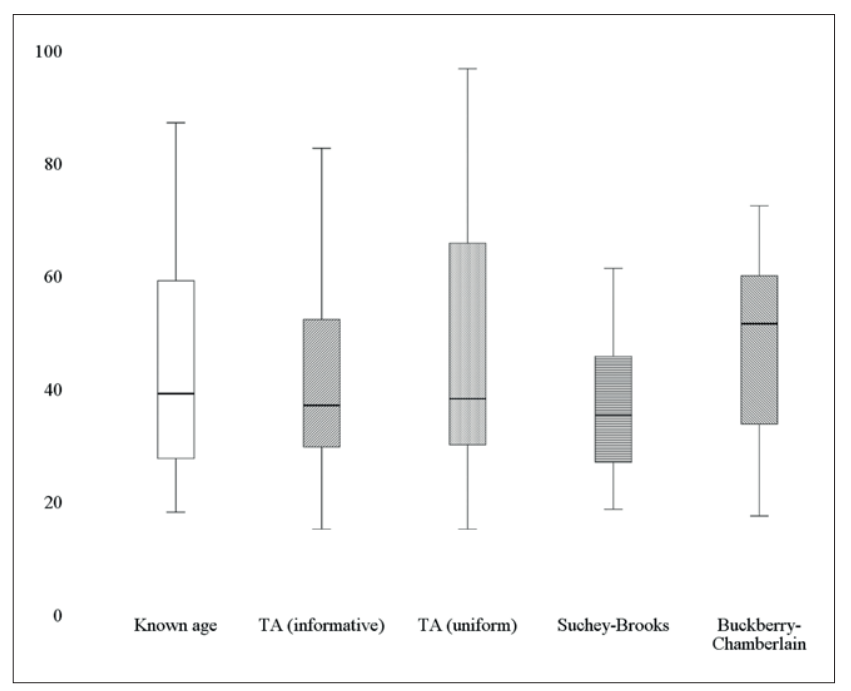

Figure 2: Boxplots with means (solid line) and 95\% confidence intervals of the age estimate distributions and the true age distribution of the sample. The distributions are created using the point estimates provided by the methods; maximum likelihood from Transition Analysis (TA) and phase means from Suchey-Brooks (1990) pubic symphysis method and Buckberry-Chamberlain (2002) auricular surface method. 


\begin{tabular}{|l|c|c|c|c|c|}
\hline Method & Accuracy \% & $\boldsymbol{r}$ & $\boldsymbol{R}^{\mathbf{2}}$ & Inaccuracy (mean) & Bias (mean) \\
\hline TA (uniform) & 73,5 & 0,807 & 0,554 & 10,5 & 2,2 \\
\hline TA (informative) & 80,9 & 0,799 & 0,571 & 8,8 & $-2,8$ \\
\hline Suchey-Brooks & 80,9 & 0,626 & 0,263 & 14,4 & $-1,7$ \\
\hline $\begin{array}{l}\text { Buckberry- } \\
\text { Chamberlain }\end{array}$ & 73,5 & 0,778 & 0,575 & 15,7 & 13,7 \\
\hline
\end{tabular}

Table 2: Results of the uniform and informative Transition Analysis (TA), Suchey-Brooks (1990) pubic symphysis method and Buckberry-Chamberlain (2002) auricular surface method. under-aged). The former is presented as a mean of the differences (sum of absolute values/number of cases), while the latter takes into consideration the sign of the value, i.e. positive versus negative (sum of values/number of cases). All material was analysed using SPSS 20. Correlation coefficients ( $r$ ) and coefficient of determinations $\left(\mathrm{R}^{2}\right)$ were also calculated for all methods. Correlation coefficients measure the strength of the linear relationship between two monotonous factors, producing a value between minus one and plus one. The further the value is from zero, the stronger the relationship. For age estimation methods a correlation of 0.7 is considered sufficient for practical application, but lower values have also been accepted (Kemkes-Grottenhaler 2002, 56). $\mathrm{R}^{2}$ exhibits the goodness-of-fit of this linear regression; how well the factor explains the event (e.g. how much of the morphological appearance can be explained by age). It acquires a value between zero and one but, according to Mays (2015), $\mathrm{R}^{2}$ values commonly remain well under 0.5 . As understanding of the non-linear relationship between age and skeletal appearance has increased, scatterplots have been recommended over $\mathrm{r}$ and $\mathrm{R}^{2}$ values (Barrett 1974; Kemkes-Grottenhaler 2002, 56-7; Corsini et al. 2005). Here, both are provided.

\section{Results}

The forensic prior was used to create the Transition Analysis age estimates. The pubic symphysis was the best singular feature $\left(r=0.71, R^{2}=0.35, n=67\right)$. The estimations acquired from the indicator (median 34.40) produced an age distribution that was the same as the true age (median 39.00) according to the Mann-Whitney test ( $U=2052.00, Z=-0.995, p=0.320$ (two-tailed)). The auricular surface $\left(r=0.66, R^{2}=0.40, n=67\right)$ also had good overall success, while the cranial sutures performed the worst $\left(r=0.5, R^{2}=0.194, n=25\right)$. Despite the wide age ranges in cranial suture closure, their exclusion from the analysis decreased the overall $r$ value of the method. When the estimations were combined, correlation increased between known age and both uniform and informative point estimates (Table 2).
A similar comparison was conducted between known ages and estimations generated by the methods of Buckberry and Chamberlain (2002) and Brooks and Suchey (1990). Though overall accuracy was good in each method, marked differences could be seen in the accuracies between age groups (Fig. 1). Accuracy rates changed according to age category, showing high accuracy among the young for Transition Analysis (forensic) informative prior and Suchey-Brooks method and among the old for the Buckberry-Chamberlain method. The effect of the age structure of the reference sample is apparent - as the target sample was skewed towards younger individuals, the Transition Analysis (forensic) informative prior and the Suchey-Brooks method were highly appropriate, whereas the older age structure of the Buckberry-Chamberlain method accounted better for older individuals.

To compare distributions between methods and known age, a boxplot (Fig. 2) was created using the point estimates from each method: the uniform and informative maximum likelihood estimates from Transition Analysis and the phase means from the Suchey-Brooks and the Buckberry-Chamberlain methods. Overall, the Suchey-Brooks method underestimated age, whereas the Buckberry-Chamberlain method overestimated age, reflecting the age structure of the reference samples. The informative Transition Analysis estimations were able to produce a distribution very close to the actual age structure of the target sample, further highlighting the importance of having an appropriate prior.

When conducting their validation study on Transition Analysis, Milner and Boldsen (2012) compared age ranges to their respective estimates. They noticed that age ranges increased with age, as could be expected, but the trend was not infinite. The age ranges created using the uniform prior plateaued after approximately seventy years and began to decline. The estimations created using the informative prior showed an even more defined pattern, the decline beginning around sixty years of age. A similar scatterplot graph was constructed here using the Series A sample results, 
Figure 3: Scatterplot comparing Transition Analysis point estimates (Maximum likelihood) and their respective age ranges intervals). With the exception offew outliers, the length of plateau and decrease after the 70-year estimate. (95\% confidence age ranges appears to

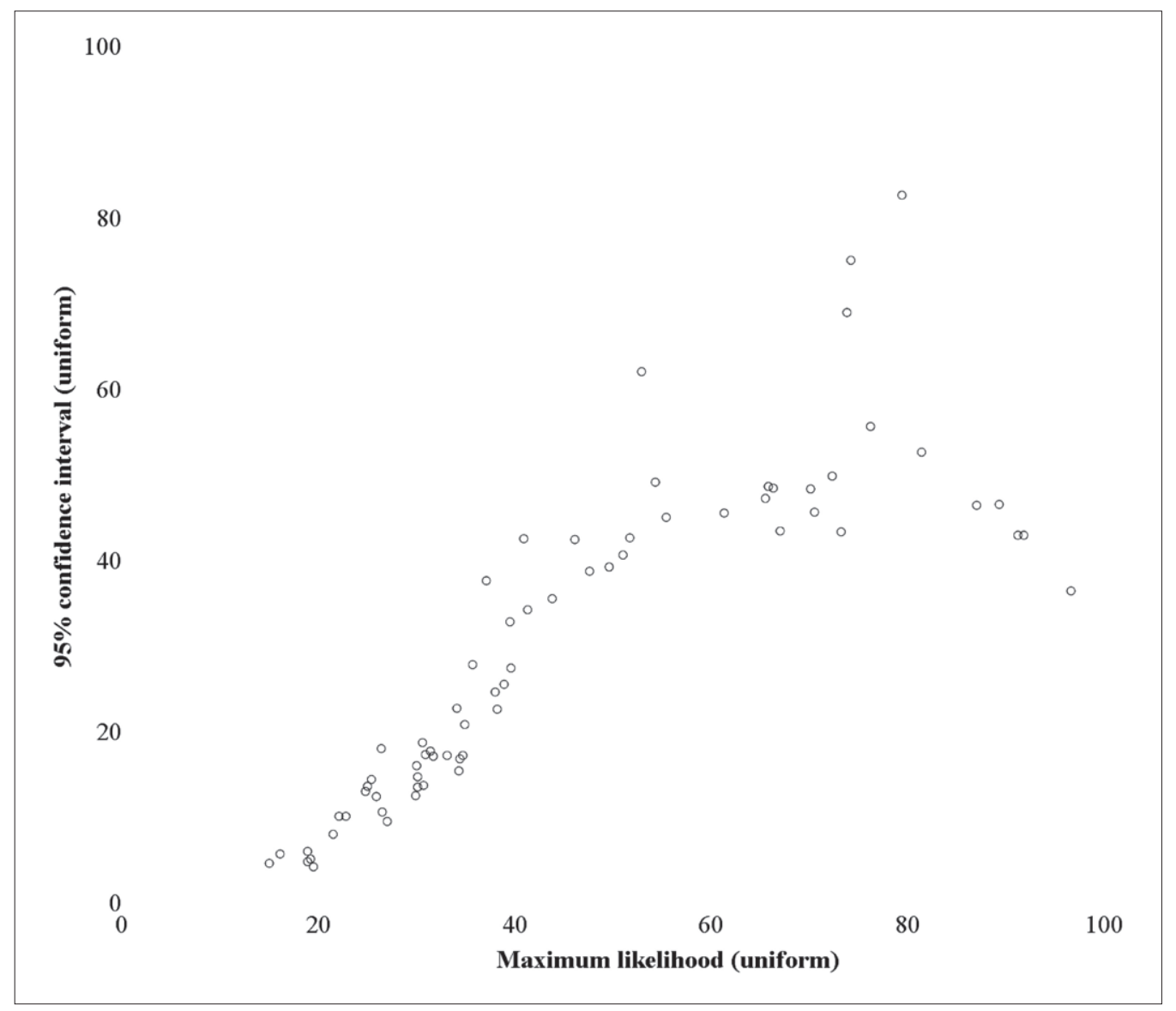

revealing a parallel pattern in uniform and informative prior estimates (Fig. 3).

\section{Discussion}

In their original test of the method, Boldsen et al. (2002) achieved high correlation values ( 0.86 for the pubic symphysis, 0.82 for the auricular surface and 0.66 for the cranial sutures with a combination of 0.88 ), advocating for further validation studies. The few validation studies conducted on Transition Analysis have not yielded as promising results, which has been suggested to be a consequence of a lack of appropriate priors (Berthard 2005, 45-6; Uhl 2008). Here, values similar to the original study were acquired, although not quite as high. The high accuracy and precision of the Series A results are probably a combination of the informative prior being incredibly appropriate and the high number of 'younger' individuals in the target sample. As is evident from the results, the informative prior was able to bring the estimations closer to the known ages, assisted by the fact that younger individuals produce more precise and accurate age estimations, regardless of the method, due to the smaller influence of accumulating extrinsic factors.
The weaker correlation between known ages and age estimations could be due to recording uncertainty, which has been previously suggested by Berthard (2005, 45-6). In the original publication (Boldsen et al. 2002, 89), a scatterplot graph was created to show the distribution of ages between stages of the dorsal symphyseal margin. While ages appeared very clustered within the stages presented by the authors, the corresponding scatterplot of the Series A individuals had much more dispersion (Maaranen 2015, 55). In addition to possible theoretical issues there are practical ones to do with the estimation process. Transition Analysis requires much more time during data collection and entry and clustered results cannot be imported from the software.

When conducting their validation study Milner and Boldsen $(2012,100)$ confirmed the residual correlations to affect the probability distributions but not the point estimates. The latter statement has been questioned by Konigsberg (2015) who tested ordinal categorical data using parametric models, focusing especially on the independence of variables. He counts the pros and cons between the mathematical models accounting for dependence and independence, the cumulative probit model used in the former and the cumulative logit model in the latter. According 
to Konigsberg $(2015,368)$ the logit model has been favoured because of its disregard to numerical integration but that 'in the modern era of statistical computing, the necessity for unidimensional numerical integration is no longer a rational basis for selecting one method over the other'.

Despite the obstacles of Transition Analysis, the method still possesses considerable advantages in comparison to other macroscopic methods. The method offers a true multifactorial option for age assessment where the error structure can be statistically analysed, avoiding the validity problems of previous attempts (e.g. Brooks 1955; Lovejoy et al. 1985a). Currently, experience-based estimations still render the best results, but the subjective nature in which they are made could create an issue if one seeks to compile and analyse results from different examiners. Creating a true multifactorial method that can mirror the experience-based estimation process would make the estimations more transparent and objective as well as statistically sound.

The informative priors may not be applicable to all cases but, when dealing with a whole cemetery population in archaeological contexts, it still offers a more suitable option than a method created from a young reference sample lacking any 'corrections'. A study published by Bullock et al. (2013) tested both conventional methods and Transition Analysis on archaeological samples from Cholula $(\mathrm{n}=147)$ and Xochimilco $(\mathrm{n}=109)$, Mexico. The results acquired from the former showed high young adult mortality whereas the distribution generated using Transition Analysis indicated a more normal demographic profile with most individuals surviving past the age of fifty years. On the other hand, if the examiner is unsure of the age structure of their target sample, one can simply opt to use the uniform prior instead which can still produce more realistic profiles of past populations (Nagaoka et al. 2012).

Another feat of Transition Analysis is the generation of individual age confidence intervals and point estimates, allowing it the ability to evaluate uncertainty case-by-case. The ability to estimate the reliability of age-related information according to skeleton is valuable, in and of itself, but it has also enabled further study of the error structures, unmasking trends not numerically proven by previous methods. The decrease of age length intervals, mentioned previously, was also noted from the Series A individuals, indicating the event is observable across larger populations. This could be caused by lack of information on skeletal changes in older adults. The updated version of Transtion
Analysis, currently underway, has begun tackling the issue (Milner et al. 2016).

The decreasing age interval lengths (regardless of cause) could offer a tangible challenge to the use of open-ended terminal intervals, especially those beginning as early as mid-life. To generate any meaningful information on age identity in past societies, or the dynamics between groups, it is essential to be able to see these groups. Maximum likelihood estimates may generate imprecision for some of the sample, but it does not generate it for the entire group. Falys and Lewis (2011) recorded an inconsistent use of age categories between publications, ranging from various numerical representations to descriptive ones, with little to no justification. Because biological age is not synonymous with either chronological or social age, age estimations and the associated age categories must be meaningful to examine the dynamics between these aspects, void of any culturally loaded terminology (Lewis 2007; Falys and Lewis 2011). The individual age intervals provided by Transition Analysis would provide a more pragmatic way of dividing adults into numerical age groups, thereby erasing some of the subjectivity.

The elderly (individuals aged over sixty years) have been estimated to have represented around 6-8\% of the population but little research exists on them (Cockayne 2003, 3; Appleby 2010). Thirty years ago, the shift in paradigm from description to interpretation was celebrated by Larsen $(1987,410)$ as 'a breakthrough that is providing the basis for a more meaningful understanding of past adaptation'. But, despite the emergence of approaches (e.g. see Buikstra 1977; Saul and Saul 1989; Armelagos and Van Gerven 2003) that offer a theoretical framework for the contextualisation of human remains in a holistic manner, many have criticised the field for the lack of applications (Gilchrist 2000; Sofaer 2006, 8-11). The trend also concerns the underpinning methodology behind different aspects of osteological investigations, where development of more sophisticated methods has had little effect on the applied practices (Falys and Lewis 2011, 713; Konigsberg 2015).

The increasing volume of literature demanding for better practices as well as pursuits to bridge the gap between theory and method have shown that there is will to improve. In addition to Transition Analysis, other mathematical models have been explored to improve age assessment, such as the probit model (Konigsberg 2015), kernel densities (Love and Müller 2002; Lucy et al. 2002; Martins et al. 2012), the Sugeno fuzzy integral (Anderson et al. 2010) and artificial neural networks 
(Corsini et al. 2005). Statistical developments have been characterised as 'not only promising, but ground breaking' (Garvin et al. 2012, 219). Precise and accurate results are an imperative for forensic work which alone is reason enough to develop better methods. While archaeological research regarding social age can use a more fluid approach and still acquire meaningful results (for which the invaluable research in this volume is a testament of), assuming better practices has the potential of bringing age identity into greater focus and will allow us to better investigate the life histories of the elderly in the past.

\section{Acknowledgements}

We thank Ilpo Hanski for granting access to study Series A at the Finnish Museum of Natural History in Helsinki. JB thanks George Milner and Lyle Konigsberg for many insightful and enjoyable conversations about age estimation, which inspired this research.

\section{References}

Anderson, M. F., Anderson, D. T. and Wescott, D. J. 2010. Estimation of adult skeletal age at death using the Sugeno fuzzy integral. American Journal of Physical Anthropology 142, 30-41.

Appleby, J. E. P. 2010. Why we need an archaeology of old age, and a suggested approach. Norwegian Archaeological Review 43, 145-68.

Armelagos, G. J. and Van Gerven, D. P. 2003. A century of skeletal biology and paleopathology: contrasts, contradictions, and conflicts. American Anthropologist 105, 53-64.

Baccino, E., Sinfield, L., Colomb, S., Baum T.-P. and Matrille, L. 2014. Technical note: the two step procedure (TSP) for the determination of age at death of adult human remains in forensic cases. Forensic Science International 244, 247-51.

Barrett, J. P. 1974. The coefficient of determination - some limitations. The American Statistician 28, 19-20.

Bayes, T. and Price, R. 1763. An essay towards solving a problem in the doctrine of chances. by the late Rev. Mr. Bayes, communicated by Mr. Price, in a letter to John Canton, M. A. and F. R. S. Philosophical Transactions of the Royal Society of London 53, 370-418.

Becker, I., Woodley, S. J. and Stringer, M. D. 2010. The adult human pubic symphysis: a systematic review. Journal of Anatomy 217, 475-87.

Berthard, J. D. 2005. A Test of the Transition Analysis Method for Estimation of Age-at-death in Adult Human Skeletal Remains. Unpublished Master's thesis, University of Tennessee.

Bocquet-Appel, J.-P. and Masset, C. 1982. Farewell to paleodemography. Journal of Human Evolution 11, 321-33.

Boldsen J., Milner, G., Konigsberg, L. and Wood, J. 2002. Transition analyses: a new method for estimating age from skeletons, pp. 73-106 in Hoppa, R. W. and Vaupel, J. W. (eds.), Palaeodemography: Age Distributions from Skeletal Samples. Cambridge: Cambridge University Press.
Brooks, S. T. 1955. Skeletal age-at-death: the reliability of cranial and pubic age indicators. American Journal of Physical Anthropology 13, 567-89.

Brooks, S. T. and Suchey, J. M. 1990. Skeletal age determination based on the os pubis: a comparison of the AcárdiNemeskéri and Suchey-Brooks methods. Journal of Human Evolution 5, 227-38.

Brothwell, D. 1981 Digging up Bones (third edition). Ithaca: Cornell University Press.

Buckberry, J. 2015. The (mis)use of adult age estimates in osteology. Annals of Human Biology 42, 323-31.

Buckberry, J. L. and Chamberlain, A. T. 2002. Age estimation from the auricular surface of the ilium: a revised method. American Journal of Physical Anthropology 119, 231-9.

Buikstra, J. E. 1977. Biocultural dimensions of archaeological study: a regional perspective, pp. 67-84 in Blakely, R. L. (ed.), Biocultural Adaptation in Prehistoric America (Southern Anthropological Society Proceedings 1). Georgia: University of Georgia Press.

Bullock, M., Márquez, L., Hernández, P. and Ruíz, F. 2013. Paleodemographic age-at-death distributions of two Mexican skeletal collections: a comparison of transition analysis and traditional aging methods. American Journal of Physical Anthropology 152, 67-78.

Chamberlain, A. 2000. Problems and prospects in palaeodemography, pp. 101-16 in Cox, M. and Mays, S. (eds.), Human Osteology in Archaeology and Forensic Science. London: Greenwich Medical Media.

Chamberlain, A. 2006. Demography in Archaeology. Cambridge: Cambridge University Press.

Cockayne, K. 2003. Experiencing Age in Ancient Rome. London: Routledge.

Corsini, M.-M., Schmitt, A. and Bruzek, J. 2005. Aging process variability on the human skeleton: artificial network as an appropriate tool for age at death assessment. Forensic Science International 148, 163-7.

DiGangi, E. and Moore, M. 2013. Future research considerations in human skeletal biology, pp. 507-12 in DiGangi, E. and Moore, M. (eds.), Research Methods in Human Skeletal Biology. San Diego: Academic Press.

Dwight, T. 1878. The Identification of the Human Skeleton. A Medico-legal Study. Boston: David Clapp \& Son, Printers.

Falys, C. G. and Lewis, M. 2011. Proposing a way forward: a review of standardisation in the use of age categories and ageing techniques in osteological analysis (2004-2009). American Journal of Physical Anthropology 156, 35-57.

Garvin, H. M. and Passalacqua, N. V. 2012. Current practices by forensic anthropologists in adult skeletal age estimation. Journal of Forensic Sciences 57, 427-33.

Garvin, H. M., Passalacqua, N. V., Uhl, N. M., Gipson, D. R., Overbury, R. S. and Cabo, L. L. 2012. Developments in forensic anthropology: age-at-death estimation, pp. 202-23 in Dirkmaat, D. C. (ed.), A Companion to Forensic Anthropology. Chichester: John Wiley \& Sons.

Gilchrist, R. 2000. Archaeological biographies: realizing human lifecycles, - courses and -histories. World Archaeology 31, 325-8.

Ginn, J. and Arber, S. 1995. 'Only connect': gender relations and ageing, pp. 1-14 in Arber, S. and Ginn, J. (eds.), Connecting Gender and Ageing: A Sociological Approach. Buckingham: Open University Press.

Gleize, Y., Castex, D. and Duday, H. 2007. An excessive ossification of costal cartilage linked to a traumatic 
pathology. Journal of Paleopathology 19, 47-56.

Godde, K. and Hens, S. M. 2012. Age-at-death estimation in an Italian historical sample: a test of the Suchey-Brooks and transition analysis methods. American Journal of Physical Anthropology 149, 259-65.

Gowland, R. 2006. Ageing the past: examining age identity from funerary evidence, pp. 143-54 in Gowland, R. and Knüsel, C. (eds.), Social Archaeology of Funerary Remains. Oxford: Oxbow Books.

Gowland, R. 2007. Age, ageism and osteological bias: the evidence from late Roman Britain. Journal of Roman Archaeology Supplementary Series 65, 153-69.

Gowland, R. L. and Chamberlain, A. T. 2002. A Bayesian approach to ageing perinatal skeletal material from archaeological sites: implications for the evidence for infanticide in Roman-Britain. Journal of Archaeological Science 29, 677-85.

Gowland, R. L. and Chamberlain, A. T. 2005. Detecting plague: palaeodemographic characterisation of a catastrophic death assemblage. Antiquity 79, 146-57.

Holman, D. J., Wood, J. W. and O'Connor, K. A. 2002. Estimating age-at-death distributions from skeletal samples: a multivariate latent-trait approach, pp. 193-221 in Hoppa, R. W. and Vaupel, J. W. (eds.), Paleodemography: Age Distributions from Skeletal Samples. Cambridge: Cambridge University Press.

Hoppa, R. D. 2000. Population variation in osteological aging criteria: an example from the pubic symphysis. American Journal of Physical Anthropology 111, 185-91.

Hoppa, R. D. and Vaupel, J. W. 2002. The Rostock Manifesto for paleodemography: the way from stage to age, pp. 1-8 in Hoppa, R. D. and Vaupel, J. W. (eds.), Paleodemography: Age Distributions from Skeletal Samples. Cambridge: Cambridge University Press.

İşcan, M. Y. 1991. The aging process in the rib: an analysis of sex and ancestry-related morphological variation. American Journal of Human Biology 3, 147-56.

İsccan, M. Y. and Loth, S. R. 1989. Research strategies in age estimation: the multiregional approach, pp. 325-39 in İșcan, M. Y. (ed.), Age Markers in the Human Skeleton. Springfield: Charles C. Thomas.

İşcan, M. Y., Loth, S. R. and Wright, R. K. 1985. Age estimation from the rib by phase analysis: white females. Journal of Forensic Sciences 30, 853-63.

İscan, M. Y., Loth, S. R. and Wright, R. K. 1984a. Age estimation from the rib by phase analysis: white males. Journal of Forensic Sciences 29, 1094-104.

İșcan, M. Y., Loth, S. R. and Wright, R. K. 1984b. Metamorphosis at the sternal rib end: a new method to estimate age at death in white males. American Journal of Physical Anthropology 65, 147-56.

Jackman, S. 2009. Bayesian Analysis for the Social Sciences. Chichester: John Wiley \& Sons, Ltd.

Johansen, H. C. 2002. Danish Population History from 1600-1939. Odense: University Press of Southern Denmark.

Katz, D. and Suchey, J. M. 1986. Age determination of the male os pubis. American Journal of Physical Anthropology 69, 427-35.

Kemkes-Grottenhaler, A. 2002. Aging through the ages: historical perspectives on age indicator methods, pp. 48-72 in Hoppa, R. D. and Vaupel, J. W. (eds.), Paleodemography: Age Distributions from Skeletal Samples. Cambridge:
Cambridge University Press.

Konigsberg, L. W. 2015. Multivariate cumulative probit for age estimation using ordinal categorical data. Annals of Human Biology 42, 366-76.

Konigsberg, L. W. and Frankenberg, S. R. 1992. Estimation of age structure in anthropological demography. American Journal of Physical Anthropology 89, 235-56.

Konigsberg, L. W. and Frankenberg, S. R. 1994. Paleodemography: 'not quite dead'. Evolutionary Anthropology 3, 92.

Konigsberg, L. W. and Frankenberg, S. R. 2002. Deconstructing death in paleodemography. American Journal of Physical Anthropology 117, 297-309.

La Fontaine, J. 1986. An anthropological perspective on children in social worlds, pp. 10-30 in Richards, M. and Light, P. (eds.), Children of Social Worlds. Cambridge: Polity Press.

Lamendin, H., Baccino, E., Humbert, J. F., Tavernier, J. C., Nossintchouk, R. M. and Zerilli, A. 1992. A simple technique for age estimation in adult corpses: the two criteria dental method. Journal of Forensic Sciences 37, 1373-9.

Larsen, C. S. 1987. Bioarchaeological interpretations of subsistence economy and behavior from human skeletal remains. Advances in Archaeological Method and Theory 10, 339-445.

Lewis, M. 2007. The Bioarchaeology of Children. Cambridge: Cambridge University Press.

Love, B. and Müller, H. G. 2002. A solution to the problem of obtaining a mortality schedule for paleodemographic data, pp. 181-92 in Hoppa, R. D. and Vaupel, J. W. (eds.), Paleodemography: Age Distributions from Skeletal Samples. Cambridge: Cambridge University Press.

Lovejoy, C. O., Meindl, R. S., Mensforth, R. P. and Barton T. J. 1985a. Multifactorial determination of skeletal age at death: a method and blind tests of its accuracy. American Journal of Physical Anthropology 68, 1-14.

Lovejoy, C. O., Meindl, R. S., Pryzbeck, T. R. and Mensforth, R. P. 1985b. Chronological metamorphosis of the auricular surface of the ilium: a new method for the determination of adult skeletal age at death. American Journal of Physical Anthropology 68, 15-28.

Lucy, D., Aykroyd, R. G. and Pollard, A. M. 2002. Nonparametric calibration for age estimation. Journal of the Royal Statistical Society 51C, 183-96.

Maaranen, N. 2015. Transition Analysis: A Validation Study on a Finnish Sample. Unpublished Master's thesis, University of Bradford.

Malghem, J., van de Berg, B. C., Lecouvet, F. E. and Maldague, B. E. 2001. Costal cartilage fractures as revealed on CT and sonography. American Journal of Roentgenology 176, 429-32.

Martins, R., Oliveira, P. E. and Schmitt, A. 2012. Estimation of age at death from the pubic symphysis and the auricular surface of the ilium using a smoothing procedure. Forensic Science International 219, 287.e1-287.e7.

Masset, C. 1989. Age estimation on the basis of cranial sutures, pp. 71-103 in İșcan, M. Y. (ed.), Age Markers in the Human Skeleton. Springfield: Charles C. Thomas.

Mays, S. 2015. The effect of factors other than age upon skeletal age indicators in the adult. Annals of Human Biology 42, 332-41.

McKern, T. and Stewart, T. 1957. Skeletal Age Changes in Young American Males: Analysed from the Standpoint of Age 
Identification. Natick: Headquarters Quartermaster Research and Development Command.

Meindl, R. S. and Lovejoy, C. O. 1985. Ectocranial suture closure: a revised method for the determination of skeletal age at death based on the lateral-anterior sutures. American Journal of Physical Anthropology 68, 57-66.

Meindl, R. S. and Russell, K. F. 1998. Recent advances in method and theory in paleodemography. Annual Review of Anthropology 27, 375-99.

Mensforth, R. P. 1990. Paleodemography of the Carlston Annis (Bt-5) Late Archaic skeletal population. American Journal of Physical Anthropology 82, 81-99.

Merritt, C. E. 2015. The influence of body size on adult skeletal age estimation methods. American Journal of Physical Anthropology 156, 35-57.

Milner, G. R. and Boldsen, J. L. 2012. Transition analysis: a validation study with known-age modern American skeletons. American Journal of Physical Anthropology 148, 98-110.

Milner, G., Boldsen, J.L., Ousley, S.D, Getz, S.M., Weise, S. and Tarp, P. 2016. Estimating age from adult skeletons: new directions in Transition Analysis using a wide array of traits. American Journal of Physical Anthropology 159, 231.

Moore, M. K. and Ross, A. H. 2013. Stature estimation, pp. 151-79 in DiGangi, E. A. and Moore, M. K. (eds.), Research Methods in Human Skeletal Biology. Oxford: Academic Press.

Mulhern, D. M. and Jones, E. B. 2005. A test of revised method of age estimation from the auricular surface of the ilium. American Journal of Physical Anthropology 126, 61-5.

Nagaoka, T. and Hirata, K. 2008. Demographic structure of skeletal populations in historic Japan: a new estimation of adult age-at-death distributions based on the auricular surface of the ilium. Journal of Archaeological Science 135, 1370-7.

Nagaoka, T., Ishida, H., Shimoda, Y., Sunagawa, M., Amano, T., Ono, H. and Hirata, K. 2012. Estimation of skeletal adult age distribution of Okhotsk people in northern Japan. Anthropological Science 120, 103-13.

Naji, S., Colard, T., Blondiaux, J., Bertrand, B., d'Incau, E. and Bocquet-Appel, J.-P. 2016. Cementochronology, to cut or not to cut? International Journal of Palaeopathology 15, 113-19.

Navani, S., Shah, J. F. and Levy, P. S. 1970. Determination of sex by costal cartilage calcification. American Journal of Roentgenology 108, 771-4.

Niinimäki, S. 2012. The relationship between musculoskeletal stress markers and biomechanical properties of the humeral diaphysis. American Journal of Physical Anthropology 147, 618-28.

Peters, K. D., Kochanek, K. D. and Murphy, S. L. 1998. Deaths: final data for 1996. National Vital Statistics Reports 47, 1-100.

Prince, D. A., Kimmerle, E. H. and Konigsberg, L. W. 2008. A Bayesian approach to estimate skeletal age-at-death utilizing dental wear. Journal of Forensic Sciences 53, 588-93.

Rejtarová, O., Hejna, P., Rejtar, P., Bukač, J., Slížová, D. and Krs, O. 2009. Sexual dimorphism of ossified costal cartilage. Radiographic scan study on Caucasian men and women (Czech population). Forensic Science International 191, 110. e1-110.e5.

Rissech, C., Wilson, J., Winburn, A. P., Turbón, D. and Steadman, D. 2012. A comparison of three established age estimation methods on an adult Spanish sample. International Journal of Legal Medicine 126, 145-55.
Sanders, C. F. 1966. Sexing by costal cartilage calcification. British Journal of Radiology 39, 233-4.

Sanders, C. F. 1971. The radiological appearances of the costal cartilages in 204 post mortem specimens. Clinical Orthopaedics and Related Research 77, 311-12.

Saul, F. P. and Saul, J. M. 1989. Osteobiography: a Maya example, pp. 287-302 in İşcan, M. Y. and Kennedy, K. A. R. (eds.), Reconstruction of Life from the Skeleton. New York: Alan R. Liss.

Saunders, S. R., Fitzgerald, C., Rogers, T., Dudar, C. and McKillop, H. 1992. A test of several methods of skeletal age estimation using a documented archaeological sample. Canadian Society of Forensic Science Journal 25, 97-118.

Schildkrout, E. 1978. Age and gender in Hausa society: socioeconomic roles of children in urban Kano, pp. 109-38 in La Fontaine, L. (ed.), Sex and Age as Principles of Social Differentiation. London: Academic Press.

Söderholm, N. 2002. Den Anatomiska Bensamlingen vid Helsingfors Universitet. Unpublished Master's thesis, University of Helsinki.

Sofaer J. 2006. The Body as Material Culture. Cambridge: Cambridge University Press.

Stigler, S. 1986. The History of Statistics: The Measurement of Uncertainty Before 1900. Cambridge: The Belknap Press of Harvard University Press.

Stuerson, B., Selvik, G. and Uden, A. 1989. Movements of the sacroiliac joints. A roentgen stereophotometric analysis. Spine 14, 162-5.

Telkkä, A. 1949. Über die Asymmetrien der Langen Gliedmassenknochen bei den Finnen. Helsinki: Tiedeakatemis.

Telkkä, A. 1950. On the prediction of human stature from the long bones. Acta Anatomica 9, 103-7.

Todd, T. W. 1920. Age changes in the pubic bone I. The male white pubis. American Journal of Physical Anthropology 3, 285334.

Todd, T. W. 1921. Age changes in the public bone. American Journal of Physical Anthropology 4, 407-24.

Ubelaker, D. H. 2010. A history of methodology in the estimation of age at death from the skeleton, pp. xvii-xxv in Latham, K. E. and Finnegan, J. M. (eds.), Age Estimation from the Human Skeleton. Springfield: Charles C. Thomas.

Uhl, N. M. 2008. ADBOU age-at-death estimation in South Africa, p. 211 in O'Rourke, D. H. (ed.), Proceedings of the American Association of Physical Anthropologists 77th Annual Meeting. Hoboken: Wiley Periodicals.

Uhl, N. 2013. Age-at-death estimation, pp. 63-90 in DiGangi, E. A. and Moore, M. K. (eds.), Research Methods in Human Skeletal Biology. Oxford: Academic Press.

Van Gerven, D. P. and Armelagos, G. J. 1983. 'Farewell to paleodemography?' Rumors of its death have been greatly exaggerated. Journal of Human Evolution 12, 353-60.

Wescott, D. J. and Drew, J. L. 2015. Effect of obesity on the reliability of age-at-death indicators of the pelvis. American Journal of Physical Anthropology 156, 595-605.

Wittwer-Backofen, U., Gampe, J. and Vaupel, W. 2004. Tooth cementum annulation for age estimation: results from a large known-age validation study. American Journal of Human Biology 122, 119-29.

Wolff, K., Hadadi, E. and Vas, Z. 2013. A novel multidisciplinary approach toward a better understanding of cranial suture closure: the first evidence of genetic effects in adulthood. American Journal of Human Biology 25, 835-43. 